\title{
Hydrophilic Portion of the Plasma Membrane
}

National Cancer Institute

\section{Source}

National Cancer Institute. Hydrophilic Portion of the Plasma Membrane. NCI Thesaurus.

Code C32748.

The faces of the lipid bilayer that are exposed to the cytoplasm and extracellular space. It is comprised of the hydrophilic heads of the lipid components, exposed surfaces and domains of transmembrane proteins, peripheral proteins and carbohydrate components. 